\title{
Clinico-Biological Profile of the Azoosperm Patient at the Urology and Andrology Department, Conakry University Hospital
}

\author{
Mamadou Diawo Bah',2, Thierno Mamadou Oury Diallo1,2, Daouda Kante1,2, \\ Lahoumbo Ricardo Gnammi 1,2, Mamadou Bissiriou Bah ${ }^{1,2}$, Demba Cisse ${ }^{1,2}$, Mamadou II. Barry ${ }^{1,2}$, \\ Ibrahima Bah",2, Abdoulaye Bobo Diallo1,2, Oumar Raphiou Bah",2, Mamadou Bobo Diallo,,2 \\ ${ }^{1}$ Urology Andrology Department of Ignace-Deen Hospital, HUC of Conakry, Conakry, Guinea \\ ${ }^{2}$ Gamal Abdel Nasser University, Conakry, Guinea \\ Email: bobodiallo@hotmail.com
}

How to cite this paper: Bah, M.D., Diallo, T.M.O., Kante, D., Gnammi, L.R., Bah, M.B., Cisse, D., Barry, M.II., Bah, I., Diallo, A.B., Bah, O.R. and Diallo, M.B. (2020) Clinico-Biological Profile of the Azoosperm Patient at the Urology and Andrology Department, Conakry University Hospital. Open Journal of Urology, 10, 300-308. https://doi.org10.4236/oju.2020.1012035

Received: September 29, 2020 Accepted: December 25, 2020 Published: December 28, 2020

Copyright $\odot 2020$ by author(s) and Scientific Research Publishing Inc. This work is licensed under the Creative Commons Attribution International License (CC BY 4.0).

http://creativecommons.org/licenses/by/4.0/

\begin{abstract}
Objective: Azoospermia is one of the most important causes of couple infertility. The objective of our study is to report the clinical-biological profile of the azoosperm patient to the Urology-Andrology Department of the Conakry University teaching Hospital. It aims to take stock of the diagnostic management of azoospermia at this time where the world scientific community seems to be turned towards the intracytoplasmic sperm injection in the treatment of men with severe spermiological dysfunction. Patients and Method: This was a descriptive retrospective study lasting 12 months from January 1 to December 31, 2015. It collected 151 patients out of a set of 544 follow-ups for desire to have children. Were included the patients whose files contained all the information of the clinical observation (general information, reason for consultation, evolution, history, data of the physical examination) and a paraclinical assessment consisting of the FSH level and two spermograms spaced three months, confirming the diagnosis of azoospermia. Results: The mean age was 36.4 years with extremes of 23 and 56 years old. Urogenital infections (36.4\%) followed by a notion of inguinal surgery had been the main patients' history. Primary infertility accounted for $76.8 \%$ of cases. The mean duration of infertility was 6.5 years with extremes of 2 and 19 years. Azoospermia affected $27.76 \%$ of patients who consulted for the desire to have a child. It was judged secretory in $59.6 \%$ of cases, excretory in $25.8 \%$ of cases, and undetermined in $14.6 \%$ of cases. Varicocele was the main associated abnormality (46.3\%) followed by testicular hypotrophy (36.4\%). Neisseria Gonorrhoeae was the most common germ in sperm culture (21.7\%). Chlamydia serology was positive in $21.7 \%$ of patients. Conclusion:
\end{abstract}


Azoospermia affects a non-negligible proportion of men admitted by consulting for desire to have a child in our context. Strengthening the diagnostic and therapeutic arsenal is necessary to improve the care of affected patients.

\section{Keywords}

Male Infertility, Azoospermia, Conakry

\section{Introduction}

Azoospermia is the complete absence of sperm in the ejaculate [1].

It affects less than $1 \%$ of men in the general population either $5 \%$ to $15 \%$ of infertile men, and is one of the most serious causes of couple's under fertility [2] [3] [4]. Depending on the mechanism, a distinction is made between secretory azoospermia (non-obstructive) resulting from a defect in testicular sperm production, and excretory (obstructive) azoospermia linked to the existence of an obstacle on the genital tract. The combination of these two types of azoospermia is possible (mixed azoospermia) [1]. The management of azoospermia has made significant progress due to recent advances in assisted reproduction techniques and the breakthrough in the technique of intra-cytoplasmic sperm injection. It requires careful exploration of the azoosperm patient by collecting some clinical data, spermiological, hormonal, ultrasound, genetic and histological. In developing countries, obtaining these various parameters is still not possible, which makes treatment of azoospermia a constant challenge for the practitioner.

The objective of this study is to report the clinical and biological profiles of azoosperm patients diagnosed as part of their follow-up for desire for paternity in our department.

\section{Patients and Method}

The study was retrospective of 12 months, from January 1 to December 31, 2015. It focused on azoosperm patients who consulted during this period for desire for a child, after a minimum period of one year of married life, punctuated by satisfactory sexual intercourse without any notion of contraception. We included the patients whose files contained all the information of the clinical observation (general information, reason for consultation, evolution, history, data of the physical examination) and a paraclinical assessment consisting of the FSH level and two spermograms spaced three months.

The clinical parameters studied were age, duration of infertility, the susceptible history (trauma of bursa, inguinal surgery, uro-genital infections) alcoholism, smoking and associated physical abnormalities clinically detected and confirmed by ultrasound.

In addition to the spermogram made in the standardized procedure of WHO [5], the biological balance sheet contains a spermoculture, chlamydia serology, a hormonal balance (FSH, testosteronemia) and a seminal plasma examination 
that has essentially taken into account the assay of the three main specific markers of epididym ( $\alpha$-glucosidase), prostate (citric acid) and seminal vesicles (fructose). The classification according to the type of azoospermia was essentially based on the rate of FSH and the testicular hypo/atrophy detected by physical examination or ultrasound for a testicular volume less than $16 \mathrm{ml}$ [6]. So the excretory azoospermia was retained for a testicular volume superior or equal to 16 $\mathrm{ml}$ and a normal FSH rate; That of secretory was retained for, the testicular volume less than $16 \mathrm{ml}$ and/or high or low FSH rate [7]. Our data were collected on a survey sheet after a manual analysis, then entered and analyzed by the Epi Info software in version 7.2.1.

\section{Results}

151 patients constituted the size of our sample. The average age of patients was 36.4 years old. (Table 1 ) The average duration of infertility was 6.52 years old (Figure 1). For $76.8 \%$ of patients $(n=116)$ it was primary infertility and $23.2 \%$ of cases $(n=35)$ of secondary infertility. Urinary infections in $36.4 \%$ of cases ( $n$ = 55) have dominated patients histories, followed by inguinal surgery in $11.9 \%$ of cases $(\mathrm{n}=18)$ (Table 2). An active unweaned smoking has been noted in $40.3 \%$ of patients $(\mathrm{n}=54)$ and alcohol consumption was effective in $31.3 \%$ of cases $(n=42)$. Varicocele in $62.91 \%(n=95)$ was the main associated physical abnormality. It was unilateral left in $67.37 \%$ of cases $(n=64)$ and bilateral in $32.63 \%$ of cases $(\mathrm{n}=31)$ (Table 3). The assistance of the FSH realized in $142 \mathrm{pa}-$ tients was high in $58.4 \%$ of cases $(n=83)$. For $88.89 \%$ of patients $(n=88)$ testosteronemia was normal (Table 4). Alpha glycosidase, fructose and citric acid were the biochemical markers achieved in $25.83 \%$ of our patients $(n=39)$ (Table 5). Citric acid values were normal in all patients $(n=39)$ and alpha glycosidase and fructose were reduced in $30.77 \%(12 / 39)$ and $12.82 \%(5 / 39)$ cases respectively (Table 6). Azoospermia was secretory in $59.6 \%$ of patients $(n=90)$, excretory at $25.8 \%(\mathrm{n}=39)$ and indeterminate at $14.6 \%$ of patients $(\mathrm{n}=22)$ (Table 6). The chlamydia serology was positive in $21.7 \%$ of cases $(n=16)$, the Neisseria Gonorrhoeae $(n=14)$ and the Escherichia coli $(n=8$.) were the germs isolated with spermoculture respectively in $63.7 \%$ and $36.3 \%$ of positive cultures (Table 7).

\section{Discussion}

The infertility of a couple is a major public health problem. Studies agree that $15 \%$ of the couples have difficulty procreating in $2 / 3$ cases, an exclusive or associated male cause [8]. In $10 \%$ to $20 \%$ of cases, the abnormality in the infertile man is azoospermia [9].

The proportion of the azoospermia in our study was $27.76 \%$ compared to all patients who consulted in the period for infertility of the couple, which calls into question the endogenous beliefs which tend to victimize women in the absence of conception within households, in our African communities [10]. 


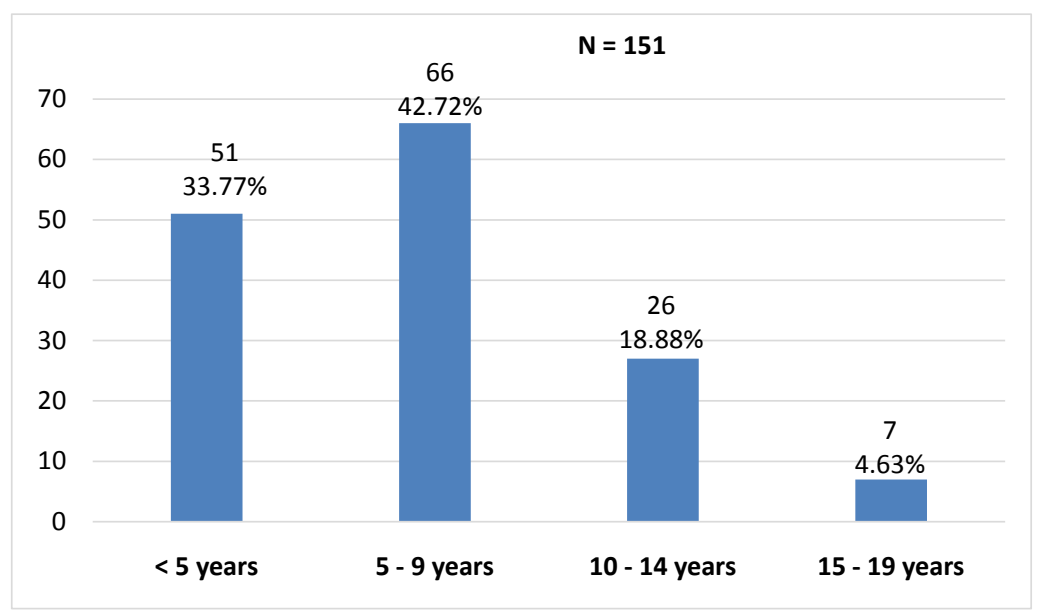

Figure 1. Duration of infertility in azoosperm patients. Average duration: 6.52 years; Extremes: 2 and 19 years.

Table 1. Age of azoosperm patients.

\begin{tabular}{ccc}
\hline Age groups (years) & Effective & $\%$ \\
\hline $18-27$ & 3 & 1.98 \\
$28-37$ & 56 & 37.08 \\
$38-47$ & 88 & 58.29 \\
$48-57$ & 4 & 2.65 \\
Total & 151 & 100 \\
\hline
\end{tabular}

Average age: 36.4 years; Extremes: 23 and 56 years.

Table 2. History of azoospermia patients.

\begin{tabular}{ccc}
\hline History & Effective & $\%$ \\
\hline Inguinal surgery & 18 & 11.92 \\
Trauma of the bursa & 5 & 3.33 \\
Uro-genital infections & 55 & 36.42 \\
\hline
\end{tabular}

Table 3. Physical abnormalities found on the patients.

\begin{tabular}{cccccc}
\hline Associated physical abnormalities & & Effective & & Total & $\%$ \\
\hline Right & Left & Bilateral & & \\
Testicular atrophy & 2 & 13 & 5 & 20 & 13.24 \\
Cryptorchidism & 7 & 7 & ----- & 14 & 9.27 \\
Testicular hypotrophy & 13 & 17 & 25 & 55 & 36.42 \\
Epididymal cyst & 1 & 5 & 1 & 7 & 4.63 \\
Varicocele & ----- & 64 & 31 & 95 & 62.91 \\
\hline
\end{tabular}


Table 4. Hormonal assessment Result.

\begin{tabular}{ccc}
\hline FSH (UI/l) & Effective & $\%$ \\
\hline $1.7-12$ & 59 & 41.55 \\
$>12$ & 83 & 58.45 \\
Total & 142 & 100 \\
Testosterone $(\mathrm{ng} / \mathrm{ml})$ & Effective & $\%$ \\
$<3$ & 3 & 3.03 \\
$3-11$ & 88 & 88.89 \\
$>11$ & 8 & 8.08 \\
Total & 99 & 100 \\
\hline
\end{tabular}

Table 5. Result of biochemical markers assay $(n=39)$.

\begin{tabular}{cccc}
\hline Biochemical markers & & Effective & $\%$ \\
\hline \multirow{2}{*}{$\alpha$-glycosidase } & Normal & 27 & 69.23 \\
& Low & 12 & 30.77 \\
Fructose & Normal & 34 & 87.18 \\
& Low & 5 & 12.82 \\
Citric acid & Normal & 39 & 100.00 \\
& Low & 0 & ---- \\
\hline
\end{tabular}

Table 6. Type of azoospermia and clinico-biological data $(n=151)$.

\begin{tabular}{lllll}
\hline \multirow{2}{*}{ Clinico-biological data } & \multicolumn{4}{l}{ Azoospermia type $(\mathrm{n}=151)$} \\
\cline { 2 - 5 } & $\mathrm{S}^{*}(\mathrm{n}=90)$ & $\mathrm{E}^{* *}(\mathrm{n}=40)$ & $\mathrm{Und}^{* * *}(\mathrm{n}=19)$ & \\
\hline High FSH & $81 / 83$ & $0 / 83$ & $2 / 83$ & 54.97 \\
Testicular hypo/atrophy & $50 / 55$ & $0 / 55$ & $5 / 55$ & 36.42 \\
Cryptorchidism Epididymal cyst & $13 / 14$ & $0 / 14$ & $1 / 14$ & 9.27 \\
Varicocele & $0 / 7$ & $4 / 7$ & $3 / 7$ & 4.63 \\
Seminal biochemistry disturbed & $59 / 95$ & $25 / 95$ & $11 / 95$ & 62.91 \\
\hline
\end{tabular}

$S^{*}$ : Azoospermia type; $E^{\star *}$ : Excretory azoospermia; Und $d^{* * *}$ Undetermined azoospermia.

Table 7. Sperm culture results from azoosperm patients.

\begin{tabular}{ccc}
\hline Sperm culture & Effective & $\%$ \\
\hline Negative & 80 & 78.4 \\
Positive & 22 & 21.6 \\
E. coli & 8 & 36.3 \\
N. gonorrhea & 14 & 63.7 \\
Total & 102 & 100 \\
\hline
\end{tabular}


The average age of our patients was relatively high compared to that of azoospermia patients of developed countries that varies between 33.2 and 33.8 [11].

On average, our patients had a duration of infertility going to seven years and in the majority of cases, it was their first consultation. This time too long put to consult could explain the high average age registered by our study. For other authors, it would be the fact of the myth of the only female responsibility in the infertility of the couple [2].

The diagnosis of azoospermia is facilitated in our context by the availability and the cost more or less affordable of the spermogram. Once done, the limits of the technical equipment become a great obstacle for the practitioner to produce further explorations in order to establish etiologies with certainty. In the absence of having certainty, the search for assistance factor for the etiological diagnostic makes it possible to have an orientation.

The secretory or excretory origin of the azoospermia has rested on the criteria involving the testicular volume at the assay of the FSH rate in our patients. For KESKES, the clinical examination was sufficient to establish the secretory origin of the azoospermia based on the presence of andrologic signs (hypo/atrophy testicular, testicular epctopic) considered as revealing of a primitive disorder of spermatogenesis often associated with an increase in plasma concentrations of FSH [9].

In accordance with what is described in the literature, we found in this retrospective study, a secretory in the majority of cases. Within this patient population, 81/90 had a high FSH rate with normal testosteronemia, in almost all (88/90). Our results corroborate the fact that primitive troubles of spermatogenesis are much more common than the gonadotropic deficits in the azoospermia cases [12].

The excretory origin of azoospermia was determined in $25.8 \%$ of our patients, associated in all the cases with a history of uro-genital infections. A decrease in $\alpha$-glycosidase and fructose rates was observed in $50 \%$ of these patients $(\mathrm{n}=17)$ of which, $30.77 \%$ for the first (12/39) and $12.87 \%$ for the second (5/39). The genito-urinary infectuous pathology represents a large etiological group in male infertility [13]. If in the developed countries, the $\mathrm{ABCD}$ remains the main cause of obstructive azoospermias, in our context, the high rate of cases of non-poorly treated infections is one of the factors for acquired obstruction from the seminal path [14].

The history and physical abnormalities found in our patients are all likely to have an impact on fertility. For some just as tobacco, the link with azoospermia does not seem to be classic. Cigarette smoking has negative effects on male fertility. Recent studies showed an active transfer of several components of cigarettes through the blood-testis barrier. The presence of these components in the seminal plasma may induce a degradation of sperm parameters and nuclear quality of spermatozoa, and compromise the chances of pregnancy. [15].

On the other hand, with some such as cryptorchidia, urogenital infections and 
the notion of inguinal surgery, the literature data appear to agree on the existence of a link with the occurrence of azoospermia.

Cryptorchidia is recognized as one of the main risk factors of azoospermia in $15 \%$ to $20 \%$ of cases [16].

In addition to being at the origin of azoospermia by obstruction of spermatic channels, the infections of the uro-genital paths are not only known to be at the origin of a leucospermia generating an oxidizing stress for sperm but also to be producing anti-spermaticozoid antibodies [17].

Inguinal surgery came to the second rank of the history found in our patients. Because of the presence of the spermatic cord, it is associated with any surgical act realized in this anatomical region of the body, a risk of iatrogenic damage on its elements. Two mechanisms reflect the possibility of occurrence of azoospermia in this type of patient: the damage of vascular structures resulting in ischemic orchitis, a testicular atrophy or endocrine dysfunction on the one hand and compression or even the stenosis of the canal defects on the other hand. When existing, these damage mechanisms can only compromise fertility in particular in case of bilateral surgery or pre-existing deficiency of the controalateral testis [1]. Varicocele has been the main physical anomaly found in our patients. It was dominant on the left (63.75\%) and bilateral in $36.25 \%$. The difficulty in the analysis of the results was the impossibility of determining whether it had a role in the occurrence of the azoospermia or if it were a simple association. Admittedly, the oligo-astheno-theratorspermia remains the most characteristic spermiological anomaly of varicocele, [18] but azoospermia may result from the ultimate evolution of varicocele by degradation of the spermogram [2].

The retrospective nature of this study was the main limitation. from the fact, some balance sheet, such as seminal plasma analysis and bursa ultrasound, could not be performed uniformly in all patients. Likewise, the lack of genetic tests and testicular biopsy were the source of missing and yet crucial variables in the etiological research of azoospermia.

\section{Conclusion}

Azoospermia is a spermiological abnormality that affects $27.76 \%$ of the men consulting in our context for child desire. It is dominated by secretory origin and the concerned patients have a profile that may be of interest to all etiologies. In the perspective of the introduction of methods of reproductive assistance, it seems imperative to strengthen the arsenal diagnosis through the development and extension of biological exploration and more efficient imaging means.

\section{Conflicts of Interest}

The authors declare no conflicts of interest regarding the publication of this paper.

\section{References}

[1] Khodari, M., Ouzzane, A., Marcelli, F., Yakoubi, R., Mitchell, V., Zerbib, P., et al. 
(2015) Azoospermie et Antécédent de Cure de Hernie Inguinale chez l'adulte. Progrès en Urologie, 25, 692-697. https://doi.org/10.1016/j.purol.2015.06.008

[2] Ndoye, M., Niang, L., Labou, I., Jalloh, M., Kane, R., Joséphine Diaw, J., et al. (2008) Azoospermies au Sénégal: Quelle Prise en Charge à l'heure de I'lCSl? Andrologie, 18, 206-209. https://doi.org/10.1007/BF03040756

[3] A Van Perperstraten, M., Proctor, M.L., Johnson, N.P. and Phillipson, G. (2008) Techniques for Surgical Retrieval of Sperm Prior to ICSI for Azoospermia. Cochrane Database of Systematic Reviews, 2008, Article ID: CD002807. https://doi.org/10.1002/14651858.cd002807.pub3

[4] American Society for Reproductive Medicine (2008) Sperm Retrieval for Obstructive Azoospermia. Fertility and Sterility, 90, S213-S218. https://doi.org/10.1016/j.fertnstert.2008.08.047

[5] Auger, J. and Jouannet, P. (1993) Valeurs de Référence des Caractéristiques du Sperme. In: Auger, J. and Jouannet, P., Eds., Manuel de Laboratoire de I'OMS. Analyse du Sperme Humain et de l'Interaction des Spermatozoïdes avec le mucus Cervical. Institut National de la Santé et de la Recherche Médicale, Paris, 45-46.

[6] Taskinen, S., Lehtinen, A., Hovatta, O. and Wikstrom, S. (1996) Ultrasonography and Colour Doppler Flow in the Testes of Adult Patients after Treatment of Cryptorchidia. British Journal of Urology, 78, 248-251. https://doi.org/10.1046/j.1464-410X.1996.05818.x

[7] Robin, G., Boitrelle, F., Leroy, X., Peers, M.-C., Marcelli, F., Rigot, J.-M., et al. (2010) Bilan d'une Azoospermie et Evaluation Histologique de la Spermatogenèse. Annales de Pathologie, 30, 182-195. https://doi.org/10.1016/j.annpat.2010.03.015

[8] Roberts, K.P. (1998) Y-Chromosome Deletions and Male Infertility: State of the Art and Clinical Implications. Journal of Andrology, 19, 255-259.

[9] Ammar-Keskes, L., Chakrou, N., Sellami Ben Hamida, A., Hadj-Kacem, L., Bouayed-Abdelmoula1, N., Ayadi, H., et al. (2007) Aspects cliniques et biologiques de l'azoospermie chez l'homme infertile en Tunisie. Andrologie,17, 71-79. https://doi.org/10.1007/BF03041157

[10] Faye, O., Moreau, J.C. and Aghonessou, M. (2000) Valeur du Test Post-Coital et de la Cytologie du Sperme dans la Stérilité Conjugale au Sénégal. Dakar Medical, 45, 138-140.

[11] Coat, C., Perrin, A., Talagas, M., Tetefort, R., Amice, J. and Valéri, A. (2011) Azoospermie: Prise en Charge et Résultats. À Propos de 90 cas. Progrès en Urologie, 21, 946-954. https://doi.org/10.1016/j.purol.2011.06.004

[12] Lejeune, H. (1999) Panorama de l’Infertilité Masculine. Andrologie, 9, 9-27. https://doi.org/10.1007/BF03034376

[13] Mieusset, R. (1998) Inflammation de l'Appareil Génital Masculin et Reproduction: Traitement in Vivo. Andrologie, 8, 259-268.

[14] Martin-Dupan, R.C., Bischof, P., Campama, A. and Morabia, A. (1997) Relationship between Etiological Factors and Total Motile Sperm Count in 350 Infertile Patients. Archives of Andrology, 39, 197-210. https://doi.org/10.3109/01485019708987917

[15] Sepaniak, S., Forge, T., Fontaine, B., Gerard, H., Foliguet, B., Guillet-May, F., et al. (2004) Impact Négatif du Tabac sur la Fertilité Masculine: Des Spermatozoïdes à la Descendance. Journal de Gynécologie Obstétrique et Biologie de la Reproduction, 33, 384-390. https://doi.org/10.1016/S0368-2315(04)96545-3

[16] Hadziselimovic, F. (2006) Early Successful Orchidopexy Does Not Prevent from Developing Azoospermia. International Brazilian Journal of Urology, 32, 570-573. 
https://doi.org/10.1590/S1677-55382006000500012

[17] Nuti, F. and Krausz, C. (2008) Gene Polymorphisms/Mutations Relevant to Abnormal Spermatogenesis. Reprod Biomed Online, 16, 504-513.

https://doi.org/10.1016/S1472-6483(10)60457-9

[18] Wagner, L. and Tostain J. (2007) Varicocèle et Infertilité Masculine: Recommandation Comité Andrologie-AFU 2006. Progrès en Urologie, 17, 12-17.

https://doi.org/10.1016/S1166-7087(07)92219-8 